\title{
The Research of Plastics-Steel Fibber Content on the Mechanical Properties of Light weight Aggregate Concrete
}

\author{
Li Yunyun, Niu Jiangang, Yang Baosheng, Li Jingjun \\ Inner Mongolia University of Science and Technology, Baotou, China
}

\begin{abstract}
In this study, lightweight aggregate concrete (LWAC) specimens with different plastics-steel fibre volumes were tested to investigate the effect of plastics-steel fibre fraction on the mechanical properties of LWAC through the experimental research and theoretical analysis. The experimental results indicated that incorporation of steel fibre into LWAC can greatly improve such mechanical properties as flexural toughness and impact resistance, but leads to a little effect on compressive strength and flexural strength.
\end{abstract}

\section{Summary}

Lightweight aggregate concrete is an ecological and environmentally-friendly building material, which has good properties such as light weight, earthquake resistance, impermeability, fire resistance and heat insulation $^{[1,2]}$. However, lightweight aggregate concrete has low compressive strength and tensile strength, large shrinkage and creep, and is prone to brittle failure. It has become an obstacle to the widespread use of lightweight aggregate concrete in load-bearing structures, and how to improve and avoid these defects becomes the focus of research in engineering and academia. Polypropylene coarse fibre is also called plastics-steel fibre. Studies have shown that mixing plastics-steel fibre in lightweight aggregate can effectively improve the brittleness characteristics of lightweight aggregate concrete $^{[3]}$. Based on this conclusion, this paper LC30 lightweight aggregate concrete without plastics-steel fibre is taken as the benchmark, and plastics-steel fibres with different volume ratios are blended in the lightweight aggregate concrete. The conventional mechanical property test is carried out to study the improvement effect of plastics-steel fibre fraction on the mechanical properties of lightweight aggregate concrete. It is hoped to obtain the rules of the changes of various mechanical indexes of light aggregate concrete with the content of plastic steel fibre, and explain the test phenomenon and failure characteristics by using the fibre reinforced and toughened mechanism.

\section{Test Overview}

\subsection{Test mix proportion}

The experimentally designed lightweight aggregate concrete has a strength grade of LC 30. The loose volume method is used to design the mix proportion of plasticsteel fibre lightweight aggregate concrete.

\subsection{Test specimen size and quantity}

The mechanical property test items are mainly the cube compression, split tensile, bending performance, and impact resistance.

Table 1. Specimen size and quantity.

\begin{tabular}{|c|c|c|c|}
\hline Test item & $\begin{array}{c}\text { Test age } \\
/ \mathrm{d}\end{array}$ & Size $/ \mathrm{mm}$ & $\begin{array}{c}\text { Number of } \\
\text { test pieces per } \\
\text { group } / \text { piece }\end{array}$ \\
\hline Cube strength & 28 & $150 \times 150 \times 150$ & $3 \times 3$ \\
\hline Split tensile & 28 & $150 \times 150 \times 150$ & 3 \\
\hline $\begin{array}{c}\text { Bending } \\
\text { performance }\end{array}$ & 28 & $100 \times 100 \times 400$ & 3 \\
\hline $\begin{array}{c}\text { Impact } \\
\text { resistance }\end{array}$ & 28 & $100 \times 100 \times 400$ & 6 \\
\hline
\end{tabular}

\section{3 experimental research}

\subsection{Experimental research on compressive performance}

The compressive strength of concrete is a basic mechanical index required by construction engineering, and it is often used as an index to evaluate the quality of concrete $^{[4]}$. The compression test is carried out in accordance with the test method in the "Testing Standards for Fibre Reinforced Concrete" (CECS13: 2009). A standard concrete cube block with a size of $150 \mathrm{~mm} \times 150 \mathrm{~mm} \times 150 \mathrm{~mm}$ is used, and each three test blocks are used as a group. 


\subsection{Experimental research on splitting tensile property}

Splitting tensile strength can reflect the tensile performance of concrete, and it is an important index to determine the concrete crack resistance and indirectly measure other mechanical properties ${ }^{[5]}$. The split tensile test was performed in accordance with the test method in the "Testing Standards for Fibre Reinforced Concrete" (CECS13: 2009). Each three test specimens are used as a group, and the size of the test specimens is $150 \mathrm{~mm} \times$ $150 \mathrm{~mm} \times 150 \mathrm{~mm}$.

\subsection{Experimental research on flexural resistance}

The flexural strength can be used to indirectly measure the tensile strength of concrete ${ }^{[6]}$. It is of great significance to conduct experimental research on the flexural performance of fibre lightweight aggregate concrete. This test is performed in accordance with the test method in Section 6.9 of the "Testing Standards for Fibre Reinforced Concrete" (CECS13: 2009).Because the length of the plastics-steel fibre used in the test is less than $40 \mathrm{~mm}$, a test specimen with a size of $100 \mathrm{~mm} \times$ $100 \mathrm{~mm} \times 400 \mathrm{~mm}$ is selected for the test. The test specimen is loaded at three points, the load acting on the test specimen is measured with a load sensor, and the mid-span deflection of the test specimen is measured by the displacement meter.

\subsection{Experimental research on flexural toughness}

Toughness is a comprehensive summary of the strength and deformation of concrete materials $\mathrm{s}^{[7]}$. At present, there is no unified method for evaluating the toughness of concrete. Japan's JCI / JSCE method and American ASTM recommended residual strength method are toughness evaluation methods that do not depend on the initial crack point, which can effectively avoid human interference. This paper combines these two evaluation methods to evaluate the toughness of plastic-steel fibre lightweight aggregate concrete.

\subsection{Experimental research on impact performance}

Impact performance refers to the ability of an object to absorb kinetic energy under repeated loads. Fibre lightweight aggregate concrete is widely used in structures subject to impacts, earthquakes, and waves due to its unique performance advantages, such as dams facing the water, high-grade roads, and bridge decks. Extensive research on the mechanical properties of fibrereinforced lightweight aggregate concrete under static force has been carried out at present ${ }^{[6,8]}$, but the research on the impact resistance under dynamic load is relatively less. So the experimental research on impact resistance under dynamic loads is necessary.
This test refers to the provisions of the ACI 544 Committee, in accordance with "Synthetic Fibres for Cement Concrete and Mortar" (GB / T21120-2007), using a home-made drop weight test device to test the impact resistance of plastics-steel fibre lightweight aggregate concrete. The test specimen is simply supported at both ends, and the span is $300 \mathrm{~mm}$, and the size of the steel backing plate is $100 \mathrm{~mm} \times 100 \mathrm{~mm} \times$ $8 \mathrm{~mm}$. During the test, the centre line of the heavy hammer is aligned with the centre line of the test specimen, and it falls freely from a height of $300 \mathrm{~mm}$. The heavy hammer hits the centre of the test block. Each impact is a cycle.

\section{Analysis of mechanical property test results}

According to the experimental study of the mechanical properties of lightweight aggregate concrete specimens with different plastics-steel fibre volumes, the results are shown in Table 2.

Table 2. Summary of mechanical property test results.

\begin{tabular}{|c|c|c|c|c|c|}
\hline number & Volume & $\begin{array}{c}\text { Compre } \\
\text { ssive } \\
\text { strength }\end{array}$ & $\begin{array}{c}\text { Flexural } \\
\text { strength }\end{array}$ & $\begin{array}{c}\text { Initial } \\
\text { energy } \\
\text { consump } \\
\text { tion }\end{array}$ & Destruction \\
\hline SJ00 & 0 & 37.48 & 4.743 & 24.255 & 28.665 \\
\hline SJ05 & 0.5 & 38.43 & 4.794 & 41.895 & 209.475 \\
\hline SJ07 & 0.7 & 39.47 & 4.667 & 81.585 & 414.540 \\
\hline SJ09 & 0.9 & 35.49 & 4.760 & 66.15 & 787.185 \\
\hline SJ11 & 1.1 & 38.58 & 4.956 & 68.335 & 2107.98 \\
\hline SJ13 & 1.3 & 37.24 & 4.862 & 70.28 & 2727.650 \\
\hline
\end{tabular}

\subsection{Effect of different volumes of plastics-steel fibres on the compressive strength of lightweight aggregate concrete cubes}

According to the test results (as shown in Table 2), the linear regression analysis is performed on the relationship between the compressive strength of plastics-steel fibre lightweight aggregate concrete and the fibre content. The regression curve is shown in Figur

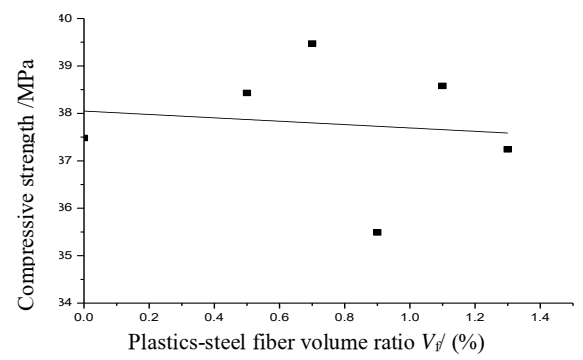

Fig. 1. The linear regression on the compressive strength and the fibre content.

It can be seen from Figure 1 that the linear relationship between the compressive strength of the test specimen and the fibre content is not obvious, and the test data has a large degree of dispersion, indicating that 
the plastics-steel fibre content has little effect on the compressive strength of the plastics-steel fibre lightweight aggregate concrete.

Compressive strength experimental results show that the ultimate failure form of ordinary light-weight aggregate concrete is damaged to the corner pyramid, which is a typical brittle failure form. After being mixed with plastics-steel fibre, the test block maintains a good integrity during the compression process, cracks without breaking, and the compressive toughness is significantly improved. This is because the fibre is incorporated into the light aggregate concrete to form a three-dimensional network support system. After the test block is cracked under pressure, the plastics-steel fibres that cross the crack play a role in preventing the crack from expanding, limiting the stress along the cracks between the aggregates. The cracks between the aggregates are restricted from expanding and penetrating in the direction of the force.

\section{2 effect of different volumes of plastics-steel fibres on the split tensile strength of lightweight aggregate concrete}

During the test, it is shown that when the fibre-free lightweight aggregate concrete is subject to splitting load, the specimen cracked in a very short time. After cracking, the specimen crack instantaneously and is broken along the full section of the crack. The light aggregate concrete mixed with plastic-steel fibre has a significantly improved failure morphology when subjected to splitting and tensile loads. The cracking process lasts longer, and the crack width is smaller, and the specimen cracks continuously. The appearance of this type of failure is mainly due to the fact that plastic-steel fibres mixed with lightweight aggregate concrete can have a good tie effect on the concrete on both sides of the crack and play a role in inhibiting the development of cracks. The specific results are shown in Table 3.

Table 3. Splitting tensile strength of test specimens.

\begin{tabular}{|c|c|c|c|c|c|}
\hline number & $\begin{array}{c}\text { Split } \\
\text { tensile } \\
\text { strength }\end{array}$ & number & $\begin{array}{c}\text { Split } \\
\text { tensile } \\
\text { strength }\end{array}$ & number & $\begin{array}{c}\text { Split } \\
\text { tensile } \\
\text { strength }\end{array}$ \\
\hline SJA00 & 2.76 & SJB00 & 2.65 & SJC00 & 2.48 \\
\hline SJA05 & 2.91 & SJB05 & 2.83 & SJC05 & 2.75 \\
\hline SJA07 & 3.37 & SJB07 & 3.26 & SJC07 & 3.22 \\
\hline SJA09 & 3.68 & SJB09 & 3.61 & SJC09 & 3.49 \\
\hline SJA11 & 3.59 & SJB11 & 3.54 & SJC11 & 3.41 \\
\hline SJA13 & 3.49 & SJB13 & 3.44 & SJC13 & 3.32 \\
\hline
\end{tabular}

The variation curve of the tensile strength of the test specimen with the volumes of plastics-steel fibre is shown in Figure 2.

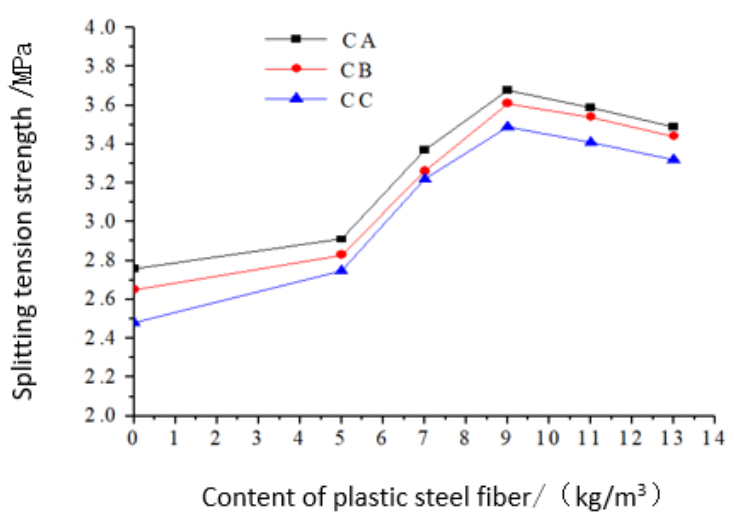

Fig. 2. The variation curve of the tensile strength of the test specimen with the volumes of plastics-steel fibre

It can be seen from Figure 2 that the split tensile strength of the three kinds of lightweight aggregate concrete increases first and then decreases with the increase of the fibre content. When the fibre content is 9 $\mathrm{kg} / \mathrm{m}^{3}$, a peak appears, which corresponds to the optimum blending amount of plastics-steel fibre under split tensile strength index

\subsection{Effect of different volumes of plastics-steel fibres on the split flexural strength of lightweight aggregate concrete}

According to the regression analysis of the relationship between the flexural strength of the plastics-steel lightweight aggregate concrete and the fibre content according to Table 2, the regression curve is shown in Figure 3.

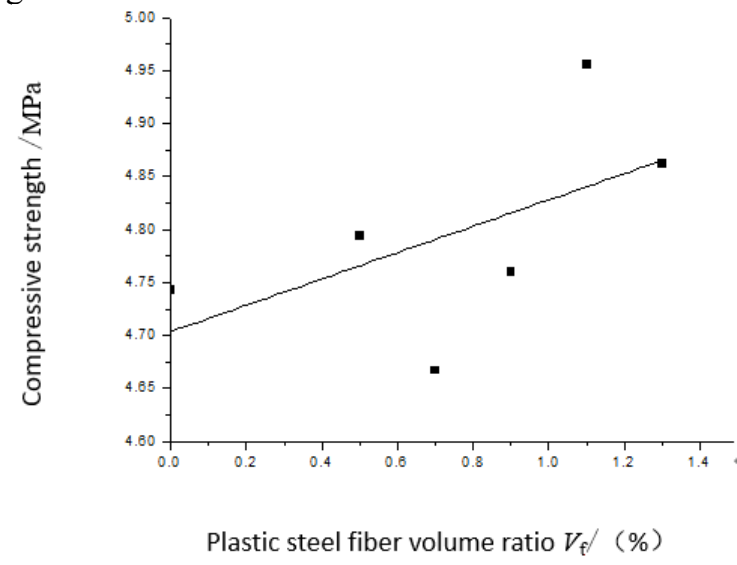

Fig. 3. the linear relationship on the flexural strength of plastics-steel fibre lightweight aggregate concrete and the fibre content

It can be seen from Figure 3 that the linear relationship between the flexural strength of plasticssteel fibre lightweight aggregate concrete and the fibre content is not obvious, and the test data has a large degree of dispersion. This is mainly due to the fact that more coarse aggregates in light aggregate concrete change the orientation of the fibre distribution, so that their distribution form cannot be distributed uniformly and randomly in three dimensions, and thus the enhancement of the flexural strength cannot be better guaranteed. 


\subsection{Experimental research on compressive performance}

The load-deflection curve of concrete with different amounts of plastic-steel fibre lightweight aggregate measured by tests is shown in Figure 4.

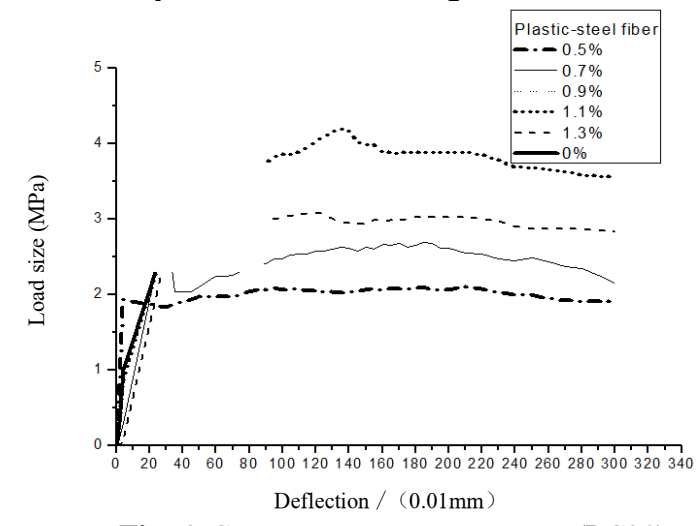

Fig. 4. Curve of load and detlection (LC30)

It can be seen from the figure that the decline of the load-deflection curve of the lightweight aggregate concrete without fibre is almost impossible to measure. After the plastics-steel fibre is added, as the volume of plastic steel fibre increases, the area covered by the loaddeflection curve is increased. It shows that the brittleness of lightweight aggregate concrete can be significantly improved by adding plastic steel fibre, and the bending toughness of lightweight aggregate concrete is improved at the same time. The main reason is that the low elastic modulus of plastics-steel fibre has a large elongation and can be added to the lightweight aggregate concrete to improve the brittle failure caused by the poor concrete tensile strength ability, increase the ductility of the lightweight aggregate concrete, and improve its plastic deformation ability.

\section{Conclusion}

(1) When plastics-steel fibre is added, the compressive strength and flexural strength of LC30 lightweight aggregate concrete are not significantly affected, but it can significantly improve the compressive failure characteristics of lightweight aggregate concrete and increase the flexural toughness of lightweight aggregate concrete. The flexural toughness makes the lightweight aggregate concrete change from brittle failure to a certain shape of plastic failure under compression, and the specimen can continue to bear the load after bending and cracking.

(2) With the increase of plastics-steel fibre content, the bending residual strength of light aggregate concrete specimen increased, indicating that adding a certain amount of plastics-steel fibre to lightweight aggregate concrete can significantly improve its bending toughness.

(3) The low elastic modulus plastics-steel fibre has strong deformation ability. When it is mixed into the lightweight aggregate concrete, specimen can still have good energy consumption after cracking, which greatly improves the impact resistance of the lightweight aggregate concrete and increase the number of impact damage resistance.

\section{References}

1. Yang Yushan, Shi Jianjun, Huang Zhigang. Experimental Research on Carbon Fibre Reinforced Lightweight Aggregate Concrete. J. Concrete and Cement Products, 6 (2007)

2. Gao Jian ming, Sun Wei, Morino Keiji. Mechanical Properties of Steel Fibre Reinforced High-Strength Lightweight Concrete. J. Cement and Concrete Composites, 19(1997)

3. Niu Jiangang, Li Boxiao, Zhang Zhen. Experimental study on mechanical properties of fibre-reinforced lightweight aggregate concrete. J. Concrete, 11(2013)

4. Qian Jueshi. Building Materials Science. M. Wuhan: Wuhan University of Technology Press, 2007

5. Dong Xiang. Study on physical and mechanical properties, frost resistance and microstructure of fibre-reinforced high-performance lightweight aggregate concrete. D. Nanjing: Master's Degree Thesis of Southeast University, 2005

6. Kayali, O. Haque, M.N. Zhu, B. Some characteristics of high strength fibre reinforced lightweight aggregate concrete. J. Cement and Concrete Composites, 25(2003)

7. ACI Committee 544. ACI544. 2R-89. Measurement of properties of fibre reinforced concrete. ACI manual of concrete practice. S. Amerian Concrete Institute, 1996

8. Li Dan, Tao Junlin, Jia Bin. Experimental study on impact resistance of basalt fiber-reinforced concrete . J. New Building Materials, 12 (2012) 